\title{
A formação do Brasil pelo aluno de poesia Oswald de Andrade
}

\author{
Cláudia Mentz Martins*
}

Resumo: Este trabalho se propõe discutir como Oswald de Andrade apresenta a formação do Brasil ao longo de alguns poemas pertencentes à obra Primeiro caderno do aluno de poesia Oswald de Andrade, publicada em 1927. A presença de fatos históricos que tratam da descoberta do País, o retrato dos habitantes de ontem e de hoje, e a descrição da cidade de São Paulo são alguns dos pontos sobre os quais o poeta (o aluno de poesia) lança seu olhar e escreve versos.

Palavras-chaves: Oswald de Andrade; poesia; história nacional.

\begin{abstract}
This paper proposes to discuss how Oswald de Andrade presents the formation of Brazil through poems from Primeiro caderno do aluno de poesia Oswald de Andrade, published in 1927. Historical facts about the discovery of Brazil, portraits of inhabitants from thr past and the present, and the description of São Paulo are some topics that the poet (the poetry student) observes and uses in the writing of his poems.
\end{abstract}

Keywords: Oswald de Andrade, poetry, national history.

O nome de Oswald de Andrade, geralmente, é associado às obras Memórias sentimentais de João Miramar e $O$ rei da vela. Também é relacionado a alguns versos como os do poema "Pronominais":

\author{
Dê-me um cigarro \\ Diz a gramática \\ Do professor e do aluno \\ E do mulato sabido. \\ Mas o bom negro e o bom branco \\ Da Nação Brasileira \\ Dizem todos os dias \\ Deixa disso camarada \\ Me dá um cigarro. \\ (ANDRADE, 2003, p.167)
}

Freqüentes, nos livros escolares, esses versos pertencem a Pau-Brasil, um volume publicado pela editora francesa Au Sans Pareil, em 1925. Há, porém, um livro de poemas escrito por Oswald que não tem recebido a mesma atenção da crítica: trata-se de Primeiro caderno do aluno de poesia Oswald de Andrade, publicado em 1927, e que contém ilustrações realizadas pelo próprio Oswald ao longo das páginas.

\footnotetext{
* Cláudia Mentz Martins é Doutor em Letras/PUCRS, Professora Colaborador Convidado do PPG-Letras da UFRGS. É bolsista CAPES/PRODOC.
} 
Os poemas do Primeiro caderno são apresentados como pertencentes a um caderno escolar. Tanto há o intento de se passar essa impressão que, na primeira página, temos as seguintes informações: Escola: Pau-Brasil, Classe: primária, Sexo: masculino, Professora: a Poesia. Notemos que existem dados significativos aí. Primeiro, é dito claramente que, para a escritura do caderno, o aluno está imbuído das idéias difundidas no "Manifesto Pau-Brasil" (1924) redigido e divulgado por Oswald de Andrade, isto é, por ele próprio. Esse manifesto é um dos textos mais conhecidos dos primeiros anos do Modernismo brasileiro por ser aquele onde explicitamente é proposta a elaboração de uma literatura efetivamente nacional, estando nele, por exemplo, o aforismo: “A poesia existe nos fatos. Os casebres de açafrão e de ocre nos verdes da Favela, sob o azul cabralino, são fatos estéticos." (ANDRADE, 1995 , p. 41).

Segundo, fica claro que o estilo do caderno será aquele voltado ao primário, isto é, a composição dos textos não será fundada numa base erudita. Terceiro, que o dono do material é um menino, liberando seu dono de uma escrita vinculada à formação dos adultos. Por fim, que a responsabilidade pelo teor e forma do que o aluno escrever é da Poesia — sua professora - ou seja, que será repetindo ou experimentando as possibilidades diversas de redação do fazer poético que o dono do caderno aprenderá a escrever; mais especificamente, a fazer versos.

Dentre as muitas abordagens para a análise desse livro oswaldiano, talvez passe desapercebida ao leitor uma temática latente: a história do Brasil. Ao longo de várias páginas, o aluno aborda fatos históricos relativos ao descobrimento e colonização do País, fala do desenvolvimento da cidade de São Paulo e ainda faz menção a momentos da cultura nacional. A razão de muitas vezes não notarmos essa linha temática se dá pelo fato de não haver uma cronologia ou uma organização habitual dos assuntos. Temos a sensação de que, tal como uma criança, o aluno de poesia vai escrevendo seus poemas conforme eles the vão surgindo. Cada novo conhecimento é registrado no Primeiro caderno sob a forma de versos e, na sequiência em que as informações são assimiladas, novas experiências lingüísticas passam a ser testadas. Nossa proposta é, pois, analisar alguns poemas que tratam dessa temática, mostrando como o aluno de poesia Oswald de Andrade registra a história de seu país e de sua cidade, enquanto ensaia a arte de fazer poesia.

Com relação à História nacional, encontramos uma referência à chegada dos portugueses ao território brasileiro. Em “Anacronismo”, temos não apenas a descoberta do País, mas seu batismo:

O português ficou comovido de achar

Um mundo inesperado nas águas

E disse: Estados Unidos do Brasil 
(ANDRADE, 2005, p. 22)

O emprego do termo anacronismo, no título, não é posto à toa, e duas podem ser as explicações. Uma delas é voltada à crítica à história oficial, ou seja, é dito que cabe ao povo português a descoberta do Brasil, mas antes de ele chegar ao território os indígenas já o habitavam. Dessa forma, é um erro cronológico atribuir essa descoberta a um povo europeu enquanto outro povo já estava aqui estabelecido. Uma outra hipótese de análise leva em conta o desenho que acompanha o poema. Na reprodução da página em que aparece "Anacronismo", temos um barco que se aproxima de uma costa com elevações de terra e, atrás dessas, há uma cidade. Considerando isso, aqueles que descobrem o Brasil - e pensamos numa referência a qualquer época - vêem o país como um lugar de muitas possibilidades de sucesso pessoal e profissional, tal como os Estados Unidos da América, esquecendo-se de que esse sucesso, se obtido, deve-se aos indivíduos que irão acolhê-lo em sua chegada.

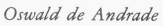

A Mârio Guastini

Anacronismo

O português ficou comovido de achar

E disse: Estados Unidos do Brasil

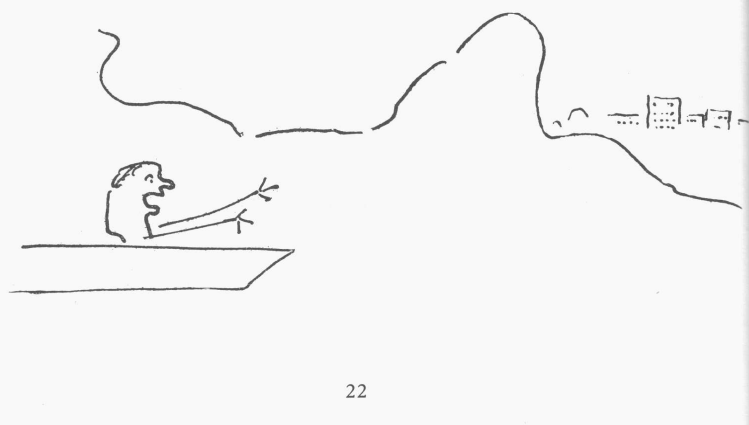

O poema "História da pátria" dá seguimento à narração dos eventos que envolvem a formação do Brasil, conforme vemos abaixo:

Lá vai uma barquinha carregada de

Aventureiros

Lá vai uma barquinha carregada de

Bacharéis

Lá vai uma barquinha carregada de 


Cruzes de Cristo
$\begin{gathered}\text { Lá vai uma barquinha carregada de } \\ \text { Donatários }\end{gathered}$
$\begin{gathered}\text { Lá vai uma barquinha carregada de } \\ \text { Espanhóis }\end{gathered}$
Paga prenda
Prenda os espanhóis
Flibusteiros
Lá vai uma barquinha carregada de
Lá vai uma barquinha carregada de
Lá vai uma barquinha carregada de
Holandeses
Lá vem uma barquinha cheiinha de índios
Outra de degradados
Outra de pau de tinta
Até que o mar inteiro
Se coalhou de transatlânticos
E as barquinhas ficaram
Jogando côa raça misturada
No litoral azul do meu Brasil
(ANDRADE, 2005, 32-33)

Ao longo desse poema, os principais acontecimentos do período da descoberta e da colonização aparecem mencionados. Isso ocorre pela menção a seus mais significativos indivíduos, entre eles: os aventureiros, os jesuítas, os colonizadores de diferentes nacionalidades. Pessoas essas e outras que, em função de terem se encontrado na terra brasileira, resultaram na sua miscigenação.

A construção do poema, composto por três estrofes, também deve ser analisada. Observamos que, na primeira, o verso "Lá vai uma barquinha carregada de" aparece repetida oito vezes, intercaladas por um verso - às vezes composto por uma só palavra - que lhe completa o sentido e que faz a história contada progredir. Essa construção em paralelismo mostra-se característica dos textos recitados pelas crianças por ser de fácil memorização uma vez que os versos mais longos permanecem inalterados e apenas uma pequena parte, que lhe complementa, muda. Também a brincadeira infantil de escrever cada verso usando uma letra do alfabeto - obedecendo a sua ordenação - é usada. Os versos pares 2,4,6,8,10,14,16,18, formados pelas palavras que fazem a história narrada seguir adiante e, por conseqüência, o poema, são iniciados pelas primeiras letras do alfabeto: "Áventureiros", "B彑acharéis”, "Cruzes de Cristo", "Donatátios", "Espanhóis" e assim sucessivamente até "ㅂolandeses”. Esse tipo de jogo com a escritura, além de ser uma brincadeira que a criança realiza com a língua, é uma maneira de o aluno decorar sua lição e, portanto, saber a história oficial do Brasil. A quebra da construção, que ocorre nos versos 11 e 12, ainda se apresenta como um experimento, desta 
vez sonoro, pois "Paga prenda/prenda os espanhóis" traz não só uma aliteração destacada do /p/ como tem a repetição da palavra "prenda", empregada de forma distinta: como substantivo e significando, nos jogos infantis, algo que se deve entregar a alguém ou alguma ação que se deve executar por ter perdido e sofrido penalidades; e, depois, como verbo "prender". A sonoridade é também auxiliada pela repetição de "espanhóis", nos versos 10 e 12.

As duas estrofes seguintes, dois tercetos, apresentam uma estrutura mais simples. A segunda estrofe se diferencia da anterior ao iniciar com "Lá vem uma barquinha [...]", e as trocas que por meio dela se realizam entre a nova terra e o velho mundo. Do Brasil saem índios e pau de tinta, elementos exóticos na Europa, e nele entram degradados, deixados aqui por ordem da Corte. A terceira estrofe se refere ao final do período de exploração da terra, marcado pelo desenvolvimento da navegação e da miscigenação ocorrida com a mistura das raças no território brasileiro.

Fazendo um salto temporal, o aluno de poesia retrata a evolução de São Paulo através de sua perspectiva. Mostra, a partir de indícios do cotidiano, como a pequena cidade deixou esse patamar para se tornar uma metrópole. No trecho, temos um exemplo:

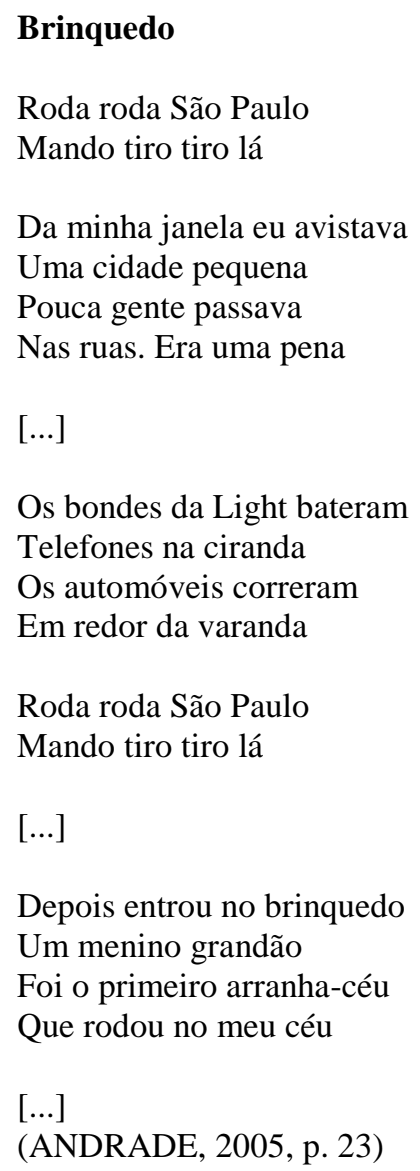

No poema "Brinquedo", o menino descreve que, antes do crescimento de São Paulo, via a cidade de sua janela, dando-nos a impressão de que conseguia abarcá-la toda nesse 
enquadramento, bem como as poucas pessoas que a habitavam. Menciona existir agora elementos modernos como os bondes da Light, os telefones, os automóveis, os arranha-céus. Essa mudança, ao contrário de entristecê-lo, é visto de forma positiva devido a indícios que deixa ao longo da construção do poema. Por se assumir como criança, o aluno deve ter nas brincadeiras seus momentos mais alegres e ao nomear o poema como "Brinquedo" transfere esse sentimento para o texto. O brinquedo também pode ser, para ele, a apropriação que faz da cantiga de roda "Mando Tiro", que garante a permanência do tom infantil da escritura. A inspiração nessa música é evidente no dístico "Roda roda São Paulo/Mando tiro tiro lá" que funciona como refrão no poema. A recuperação da idéia da brincadeira está expressa em "Roda roda São Paulo" que de imediato alude a formação das crianças de mãos dadas a girar e da utilização do verso seguinte idêntico ao da cantiga.

Nesse poema, a atenção se volta ainda para o desenho feito abaixo da última estrofe. A ilustração realizada pelo aluno retrata a cidade de São Paulo descrita ao longo dos versos: se por um lado é moderna com automóvel, fábrica, grandes prédios, postes de iluminação elétrica, não esquece do teor conservador do local, lembrando-se de inserir uma igreja na paisagem. A marca da época da escritura fica destacada com a exclamação "Viva Tarsila!", a esposa de Oswald no período e autora de alguns quadros célebres como duas telas intituladas São Paulo de 1924. 


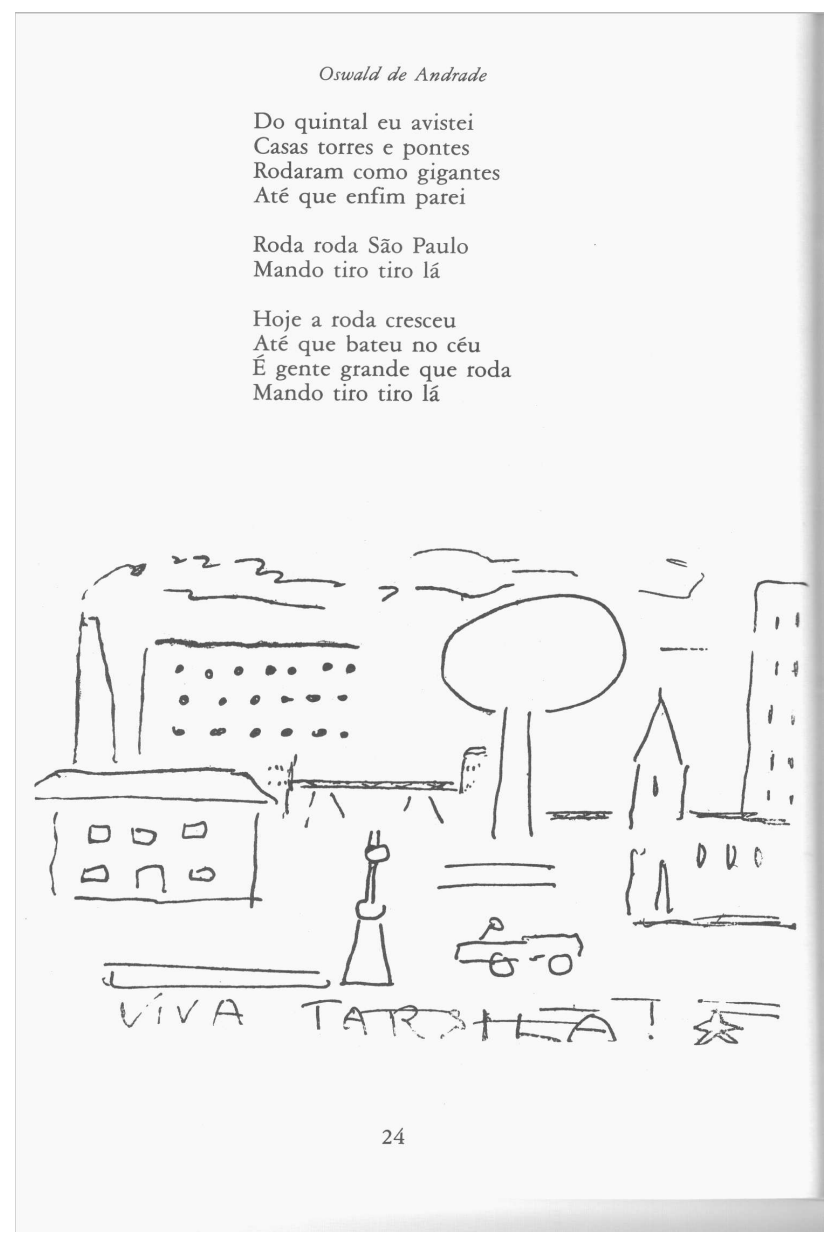

O poema que encerra o livro — antes dos fragmentos inéditos —, "Canção da Esperança de 15 de novembro de 1926”, tem a data muito próxima a da publicação do Primeiro caderno. Assim, supomos ser um dos últimos versos que o aluno escreveu em seu material, aproximando sua produção, seus conhecimentos adquiridos na escola à época em que vive. De modo sucinto, as estrofes relatam toda a movimentação em torno do desfile em comemoração à Proclamação da República: há a descrição do dia, das pessoas que presenciam a solenidade, dos soldados que dela participam:

O céu e o mar

Atira anil

No meu Brasil

Sobre a cidade

Flutua

A bandeira do Porvir

Cada árvore

De estanho

Plantada

Espera

A passagem

Da carruagem

Do presidente

Do Brasil 


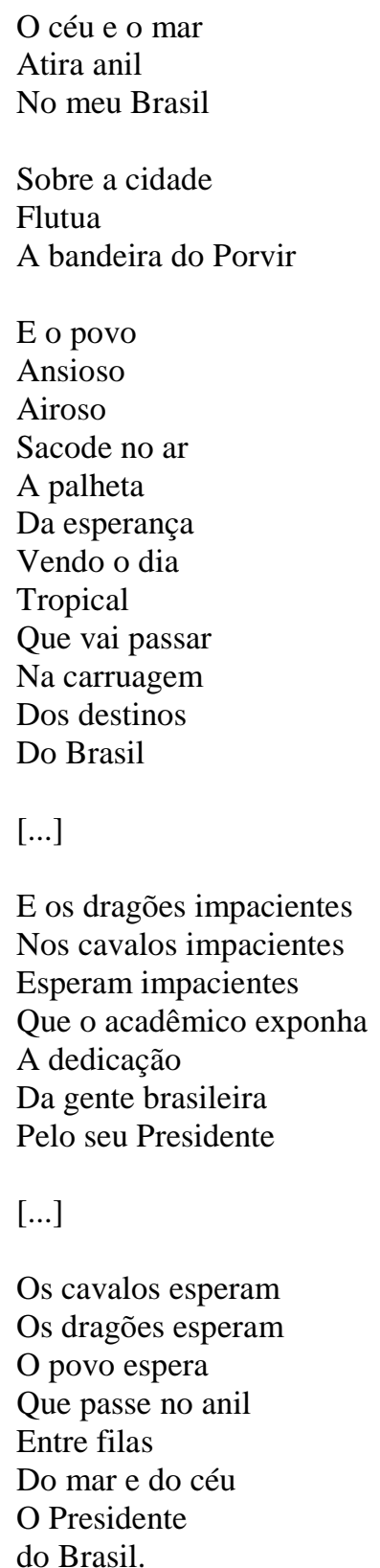

(ANDRADE, 2005, p. 49-51)

Como em outros poemas do Primeiro caderno, a presença da musicalidade é evidente na composição das estrofes. A marca inicial está no próprio título "Canção da Esperança", reforçada pela repetição dos versos das duas primeiras estrofes nas estrofes 4 e 5; na repetição de "impacientes" na $8^{a}$ estrofe, em seus três versos iniciais, e na última estrofe, também nos três primeiros versos, do verbo "esperar". O ritmo, acentuado por essas repetições e pelas rimas externas, dá poema uma agilidade que reforça a idéia de festa presente na descrição do desfile. Como todo poema trata da expectativa ocasionada pela espera da passagem do Presidente do Brasil, o espetáculo ganha destaque ao longo dos versos. Não esqueçamos que datas como a em pauta tendem a fazer o povo valorizar a pátria, a demonstrar amor ao solo 
nacional e, com isso, manter a crença de que os problemas da nação serão resolvidos, restabelecendo-se a esperança em dias melhores.

Ao longo dos poemas selecionados, temos uma amostra de como o aluno Oswald de Andrade vê a história nacional. Ele aponta os principais episódios da formação do Brasil de modo crítico, isto é, deixando claro seu posicionamento sobre eles, o que é percebido pelo tom humorístico que alguns fatos ganham no Primeiro caderno. Todavia, o riso não é gratuito, afinal, sua presença objetiva chamar a atenção do leitor para os eventos relatados, gerando uma reflexão do leitor. O conteúdo aprendido na escola, quase sempre não questionado pelos educandos, ganha novo olhar, que produz um novo sentido que, por sua vez, leva a uma maior compreensão da história do País. O aluno, fazendo uso de versos que se configuram quase infantis numa primeira (e desatenta) impressão - busca dar um novo sentido ao fazer poético, inspirado na liberdade estética inaugurada em 22 e na proposta da mesma época de se repensar o Brasil, seu passado e presente, a fim de se tentar estabelecer uma nova perspectiva para a arte e cultura nacional.

\section{Referências}

ANDRADE, Oswald. Primeiro caderno do aluno de poesia Oswald de Andrade. São Paulo: Globo, 2005. . Manifesto da Poesia Pau-Brasil. In: A utopia antropofágica. São Paulo: Globo, 1995. p. 41-45.

ANTELO, Raúl. Prefácio. In: ANDRADE, Oswald. Primeiro caderno do aluno de poesia Oswald de Andrade. São Paulo: Globo, 2005. p. 7-14.

CAMPOS, Harold de. Uma poética da radicalidade. In: ANDRADE, Oswald de. Poesias reunidas. 5.ed. Rio de Janeiro: Civilização Brasileira, [s.d]. p. 9-59. 